\title{
Theoretical and Applied Problems of the Polygraph Use in Criminal Proceedings in Russia
}

\author{
Komissarova Yaroslava Vladimirovna ${ }^{1 *}$ and Khamzin Said Rushanovich ${ }^{2}$ \\ ${ }^{1}$ Department of the Criminalistics, Associate Professor, Kutafin Moscow State Law University, Russia, \\ ${ }^{2}$ Member of the American Polygraph Association, British \& European Polygraph Association, Eurasian Polygraph Association and Polygraph examiner, \\ researcher, instructor.
}

Submission: December 20, 2017; Published: January 08, 2018

*Corresponding author: Komissarova Yaroslava Vladimirovna, Department of the Criminalistics, Associate Professor, Kutafin Moscow State Law University, Russia; Email: a5143836@yandex.ru

Said R Khamzin, Polygraph Examiner, researcher and instructor, Member of the American Polygraph Association, British \& European Polygraph Association, Eurasian Polygraph Association, Russia, Email: saidhamzin@gmail.com

\begin{abstract}
The article gives a concept of polygraphology as an interdisciplinary field of knowledge. The tasks, which are submitted for the resolution by a polygraph examiner who participates in the court proceedings as an expert, are formulated. An algorithm for formulation of the conclusions of an expert polygraph examiner is described. Some logical errors, made by polygraph examiners during formulation of the conclusions based on the results of the examination are pointed out. The concepts of "validity" and "reliability" are differentiated with the regard to the conducting of the forensic polygraph examinations on criminal cases.

Keywords: Polygraph Examination; polygraphology; Criminal Proceedings; Expert Polygraph Examiner; Expert Version; Reliability of the Expert Conclusions
\end{abstract}

\section{Introduction to the problem}

Today in Russia, as well as in many other countries, polygraph is actively used:

a. During the investigative activities in accordance with the legislation of the Russian Federation, which regulates such activities;

b. In the course of court proceedings in accordance with the procedural legislation of the Russian Federation;

c. Upon entry into the career government service (including military) and active service in accordance with the legislation of the Russian Federation;

d. In regulation of labor and other directly related relations in accordance with the labor legislation and acts, that regulate the employment;

e. Providing the services in accordance with the civil services agreements.

f.Criminal Procedure Code of the Russian Federation allows to publicly involving polygraph examiners into the criminal proceedings as an expert (Article 57) or as a specialist (Article 58).

As a general rule, when special knowledge (knowledge from any field, except legal) is required for the investigation of the issues, which are relevant to the case, investigator or a judge may appoint a person who possess such knowledge as an expert or a specialist. Expert's report and testimony as well as specialist's report and testimony are independent evidences on a criminal case. According to the Part 2 of the Article 195 of the Criminal Procedure Code of the Russian Federation, forensic expert examination is conducted by the government forensic experts, but any person who possess special knowledge, can be assigned to conduct such an examination.

Therefore, in a regard to the forensic psychophysiological polygraph examination (hereinafter - FPPE) practices, a scientific problem arises, which has an important practical significance. It is necessary in any manner to specify on the formal grounds the field of knowledge, which is used by a polygraph examiner, in order for an investigator or a judge to make an evaluation of the expertise of a person, whom they appoint as an expert [1-9]. 


\section{The Concept of Polygraphology}

Obtaining information always involve work with its material form. In this sense, information, disclosed by a person (including the participants of the court proceedings) is not an exception. However, the situation of interpersonal communication is very specific, since there is a so-called psychophysiological problem. In science, there is no answer to the question of the relationship between mental and physiological processes taking place in the human body in connection with obtaining, preservation and reproduction of any information. Over the decades of the polygraph use, a significant amount of the empirical evidence that indicate the effectiveness of its use has been accumulated in many countries throughout the world. Many theories have been proposed, which reflect the attempts of scientists and practitioners to describe the nature of the detected psychophysiological reactions.

As it is known, in the beginning of the XXI century, the Committee to Review the Scientific Evidence on the Polygraph of the National Academy of Sciences was formed by the request of the US Department of Energy. The result of fundamental analysis of almost all aspects of the issue, which was conducted for 19 months, was the conclusion that the theoretical basis for the polygraph use is quite weak and different theories justify their existence in different situations. Objective misunderstanding of the essence of any phenomenon cannot be the reason for the denial of its scientific validity. In practice, the situations where mechanism of the phenomenon is first clarified, and then the applied method is formed on the basis of the obtained data occur rarely. Therefore, the presence of the stable (not deterministic, but probabilistic) cause-and-effect link between mental process and physiological reactions can be confidently used as a basic theoretical background for the effective use of polygraph for solving a variety of applied problems (including forensic).

The phenomenon underlying human psychophysiological reactions are of a complex nature. This necessitates the need for a simultaneous use of special knowledge from several fields of psychology, physiology and criminalistics during polygraph examinations. We can talk about the formation of a new interdisciplinary field of knowledge. In Russia, it was named "Polygraphology". Polygraphology is a knowledge system about the scientific and methodological foundations, technical, organizational and legal conditions for conducting of a psycho physiological examination with a use of polygraph for the examination of the informational state of the test subject within the framework of court proceedings, investigative, labor and official activities.

\section{Purpose and Objectives of Polygraph use in Court Proceedings}

During conduction of the FPPE, it is necessary to distinguish between the purpose of the examination from the position of a person, who requested the examination (investigator or a judge) and the problem of the cognitive activity of a polygraph examiner during the examination. During the initial phase of a crime investigation, while collecting the evidence, investigator obtains testimonies of victims, suspects, accused, wit ness. People do not always tell the truth. False testimony is a widespread phenomenon. Throughout the world, the investigator and the court are faced with the need for credibility assessment of the testimonies of the participants of criminal proceedings. As it is known from criminalistics and psychology, a person, called for questioning, may be in one of the four states:

a) possesses the information, which the investigator is looking for, and wishes and can objectively and fully provide it;

b) possesses the necessary information, wishes to provide it, but for various reasons unintentionally misinterprets it during the communication with investigator;

c) possesses the information, can provide it, but does not want to do it;

d) does not have any information, but investigator mistakenly believes the opposite and is trying to obtain a detailed testimony.

We believe that an investigator can appoint a number of expert examinations in order to determine the state in which the participant of the criminal proceedings might be (the issue refers to the positions 2-4). At the same time, it is necessary to distinguish between the purpose of the appointment of the expert examination from the perspective of the examination initiator, and the tasks, resolved by the expert in the course of the cognitive activity within the framework of the conducted examination. In this case, the expert task will be the identification of a set of characteristics of a certain informational state of the test subjectlinguistic, psychological, psychophysiological characteristics. The objective of a polygraph examiner is to determine in which state is the participant of the proceedings, who provides the testimony. In other words, during the polygraph examination, an expert polygraph examiner examines the informational state of the examinee.

By the means of polygraph, we "visualize" some physiological correlations of the execution of personal mental process associated with perception, fixation, preservation and subsequent replication of the information about the event, which is the matter of interest of investigation authorities and the court. First, a polygraph examiner updates the images, stored in the memory of the examinee primarily (but not only) by presenting the stimuli, selected and arranged in a certain order. Followed by the examination of the significance, stability and ratio of the reactions on stimuli. By using different systems of evaluation of the recorded information, a polygraph examiner can identify a set of stimuli, which is significant to the person.

Depending on the type of stimuli and on the technique used during a polygraph examination, a polygraph examiner can give an affirmative or a negative answer to the question: whether the 
reactions were detected or not, which indicate that the examinee possesses an information about the event or it's details?

Thus, based on the analysis of the reactions on the stimuli, a polygraph examiner formulates the expert version regarding the examinee knowledge about the incident. An examiner also has a right to make a judgment about the possible circumstances of how the examinee received the information about the event (the probability of obtaining such information directly at the time of the incident).

\section{Authority of an Expert Polygraph Examiner}

By giving to the FPPE initiator the information whether or not the person is a bearer of information regarding the particular event or its details, we must remember that a polygraph examiner has a limited toolkit for conduction of an expert examination. The modern state of science does not allow us to make a specification of the information which a person possesses by recording and analyzing the psychophysiological reactions in response to the stimuli. The mechanisms of memory are not yet fully understood. Taking into the account the specific features of the current problem in the context of the situation in which the examination is conducted, the significance of the specific stimuli, detected by polygraph, may have a different nature. It may not only indicate the deception when answering on relevant questions, but also about the examinee's recognition of the details without reference to the crime event, about the presence of any unsatisfied actual need, etc.

Even when the examinee is telling a lie, we must take into the account that the psychology makes a distinction between a known lie (false report) and an honest mistake (error report). In the first case a person, who gives a false testimony, understands that the statement does not reflect the actual facts and deliberately makes it. In the second case a person acts unintentionally. $\mathrm{He}$ does not know that the information that he provides is untrue. Regardless of whether a false or a truthful information is reported on the case by a participant of the proceedings, his condition is continuously changing under the influence of many objective and subjective factors. Polygraph records the external characteristics of the changes in the psychophysiological state of the human body. Polygraph examiners cannot be sure that every time they are presenting the stimuli they deal with the reactions to it. When the FPPE is conducted, the matter is not the question itself (and the reactions when the question is presented), but a complex of "question answer general context of the situation". During a polygraph examination, the examinee is affected by a wide range of circumstances, related to the procedure in one way or another.

\section{Common Mistakes of Polygraph Examiners in Drawing the Conclusions}

Today, the reports of polygraph examiners, appointed as experts on criminal cases, often have a mistake, known in logic as "imaginary following". It occurs when there is no logical connection between the thesis (conclusion) and arguments, which substantiate it. Polygraph examiners make this mistake when:

A. If the responses of the participant of the criminal proceedings indicated the psychophysiological reactions to the comparison questions, which exceed the significance of the reactions of the relevant questions, which were answered NO. In this case, a polygraph examiner may propose a version that the person has the information consistent with previously reported (in the part, that was covered by the test question). However, the conclusion about the absence of reactions cannot be substituted with the conclusion that the reactions, that indicate that a person possesses the information, which he previously reported, were detected. A correct formulation of the conclusion is: no reactions, indicating that the examinee has information that is contrary to what has been reported previously, were detected during the examination.

B. Wishing to support one of the parties (for various reasons, including the compassion to someone's grief), some polygraph examiners state, that "psychophysiological reactions, that were detected during the examination, are consistent with the information that the examinee had reported earlier". In reality, the reactions are indicators, which allow the detection of the informational state of the participant of the proceeding through a multistage analysis and the assessment system. The unique feature of polygraph examinations is that when formulating a conclusion, the instrument readings are not used directly. They only reflect the state and the behavior pattern of the human physiological process and do not contain any other information that could directly indicate the reliability or unreliability of the examinee's statements, especially the nature of the information that he or she possesses.

C. Often, in the absence of significant stable psychophysiological reactions on the relevant questions, presented to the participant of the proceedings, polygraph examiners make a conclusion that there are no images in his or her memory formed in connection with the event. It is unacceptable to consider the absence of reactions to relevant questions as a proof of innocence of a crime suspect. This is a major mistake. In experimental psychology, it is customary to distinguish between "accessibility" and "presence" of traces in memory. During a polygraph test, it is impossible to establish whether the "trace was completely lost" or if the event sign was not found (no proper stimulus was formed, an appropriate question was asked) that would allow a person to reproduce the sought information. In this situation, a polygraph examiner is objectively deprived of any judgment on the awareness of the person about the event that served as a reason for conducting of the examination, and the circumstances of obtaining the information, which is the subject of interest of the investigation 
authorities.

\section{Categories of "Reliability" and "Validity" in the Conduction of Forensic Examinations}

In science, it is common to distinguish between "validity" and "reliability" of knowledge and judgments based on them. Validity characterizes the relation of knowledge to the reflected object, their correspondence to each other, and the reliability of the proof of knowledge. Validity of the hypothesis, which corresponds to reality, does not initially raise doubts. But to become a reliable knowledge, it must be proven.

This applies not only to philosophy, but also to legal science. The knowledge gained during the investigation of a crime, preserved in the evidence on which the verdict is based, can also be described from two sides. First, for each of the evidence in terms of their validity (in terms of "probability" and "reliability"). Second, from the point of view of compliance or non-compliance of the evidence to the reality (in the categories "validity" and "reliability"). The probability of guilt of the accused can be high, although in fact he is not guilty. The probability of guilt of the accused can be extremely low, but, in reality, he is guilty. It all depends on what evidence on the case which the investigation authorities and the court managed to get. When we talk about actions and facts that took place in the past, the probability of the highest degree can be as far from the truth, as the probability of the lowest degree.

Similar situations are familiar to polygraph examiners throughout the world as false positive ("false alarm") and false negative ("missing the goal") error. However, not many people think about the question: who in practice commits such mistakes and bears a responsibility for them. When a polygraph examiner formulates a conclusion in the categories "Deception Indicated" or "No Deception Indicated" an examiner unreasonably accepts the risks associated with false positive and false negative errors. In fact, this is not the case.

The statements contained in the expert's report are the conclusions that an expert had made on the basis of the examination result based on the information provided or revealed about the analyzed object and the general scientific provisions of the relevant field of knowledge. By choosing the form of the conclusion (categorical positive, categorical negative, probable), the expert, taking into the account the quality and the quantity of the initial data, on the basis of his own special knowledge, evaluates the validity based on the results of the conducted examination.

If during the procedure an expert polygraph examiner acted in accordance with the available scientific and methodological standards, he has nothing to reproach himself for. A particular professional is not responsible for those limitations that are objectively related to the use of the psychophysiological method of "Lie Detection". A professional operates within its competence, relying on the information (not always complete and reliable) provided by the investigator (court) and participants in the proceedings.

For this very reason, for the investigator and for the judge, a conclusion of any expert is only an opinion of the private expert. The flat conclusion of a polygraph examiner "Deception Indicated" or "No Deception Indicated" is nothing more than his subjective opinion, which may not coincide with the opinion of his colleagues. When appointing a re-examination, they can come to diametrically opposite conclusions.

\section{Evaluation of the Expert Report As the Evidence On A Criminal Case}

The expert report, as the evidence, is a subject to an independent evaluation, which, under the Criminal Procedure Code of the Russian Federation, is conducted by the investigation authorities and the court. Regardless of the validity degree of the expert's conclusions, for various reasons, his report can be deemed as inadmissible evidence. According to Part 1 of Art. 88 of the Criminal Procedure Code, each evidence is evaluated in terms of relevance, admissibility, reliability, and all collected evidence taken together - sufficiency for the resolution of the criminal case. In this case, "reliability" is the quality of evidence that characterizes the accuracy, correct reflection of the circumstances involved in the fact to be proven. The reliability of the evidence is verified by comparing it with other evidence of the case. Detection of contradictory and conflicting information indicates the unreliability of any evidence.

The testimony of the participant in the proceedings, contrary to the established facts, is unreliable, regardless of the reasons why the person reported untrue information. It is important to understand when making a determination of certain crimes, whether a person is telling a lie intentionally or makes an honest mistake. The typical examples are the crimes against justice (for example, deliberate false denunciation). Unlike the criminal law, from the point of view of the criminal procedure law, the testimony of the proceedings participant, containing false information, is a priori (from the outset) an inadmissible evidence. In this case, the conclusion of an expert polygraph examiner, interpreted as "No Deception Indicated" following the examination of a sincerely erring participant of the process, has no evidentiary value. When analyzing the case evidence, the investigator and the court, for various reasons, can accept those of them that do not reflect the circumstances that took place in reality. Not polygraph examiners, but the judges in all countries of the world inevitably commit false positive and false negative errors when making ad judgments and sentences. It all depends on what case evidence the investigation authorities and the court managed to obtain.

\section{References}

1. Baev O Ya (1992) Tactics of the Investigative Activities: a textbook. Voronezh.

2. Engalychev VF, Kravtsova GK, Kholopova EN (2017) On the Possibility of the Conduction of the Forensic Psychological Expert Examination for the Identification of Signs of Reliability/Unreliability of Information Obtained from Participants of Criminal Proceedings. 
3. Komissarova Ya V (2016) Basics of the polygraphology: a textbook for Master's students.

4. Komissarova Ya V (2014) Professional Activities of the Expert in Criminal Proceedings: Theory and Practice 4(4).

5. Ovsyannikov I V (2001) The Probability Concept in Forensic Examination and in Proof on the Criminal Cases.

6. Orlov Yu K (2005) Forensic examination as an instrument of evidence in criminal proceedings.
7. Pelenitsyn AB, Soshnikov AP (2011) On Scientific Basis of Polygraph Use.

8. Pop chuk OM (2006) Linguistic and Paralinguistic Implementations of False Statement in Communications Act.

9. Semenov VV, Ivanov LN (2008) Legal, tactical and methodological aspects of polygraph use in criminal proceedings: a textbook.

\section{Your next submission with Juniper Publishers will reach you the below assets}

- Quality Editorial service

- Swift Peer Review

- Reprints availability

- E-prints Service

- Manuscript Podcast for convenient understanding

- Global attainment for your research

- Manuscript accessibility in different formats ( Pdf, E-pub, Full Text, Audio)

- Unceasing customer service

Track the below URL for one-step submission https://juniperpublishers.com/online-submission.php 